\title{
Evaluating the Small Population Paradigm for Rare Large-Bodied Woodpeckers, with Implications for the Ivory-billed Woodpecker
}

\section{Évaluation du paradigme des petites populations pour les pics de grande taille et implications pour le Pic à bec ivoire}

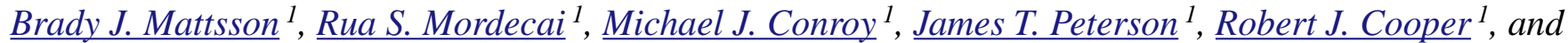 \\ $\underline{\text { Hans Christensen }}^{2}$
}

\begin{abstract}
Six large-bodied, $\geq 120 \mathrm{~g}$, woodpecker species are listed as near-threatened to critically endangered by the International Union for Conservation of Nature (IUCN). The small population paradigm assumes that these populations are likely to become extinct without an increase in numbers, but the combined influences of initial population size and demographic rates, i.e., annual adult survival and fecundity, may drive population persistence for these species. We applied a stochastic, stage-based single-population model to available demographic rates for Dryocopus and Campephilus woodpeckers. In particular, we determined the change in predicted extinction rate, i.e., proportion of simulated populations that went extinct within $100 \mathrm{yr}$, to concomitant changes in six input parameters. To our knowledge, this is the first study to evaluate the combined importance of initial population size and demographic rates for the persistence of largebodied woodpeckers. Under a worse-case scenario, the median time to extinction was 7 yr (range: 1-32). Across the combinations of other input values, increasing initial population size by one female induced, on average, $0.4 \%-3.2 \%$ (range: $0 \%-28 \%$ ) reduction in extinction rate. Increasing initial population size from 5-30 resulted in extinction rates $<0.05$ under limited conditions: (1) all input values were intermediate, or (2) Allee effect present and annual adult survival $\geq 0.8$. Based on our model, these species can persist as rare, as few as five females, and thus difficult-to-detect, populations provided they maintain $\geq 1.1$ recruited females annually per adult female and an annual adult survival rate $\geq 0.8$. Athough a demographicbased population viability analysis (PVA) is useful to predict how extinction rate changes across scenarios for life-history attributes, the next step for modeling these populations should incorporate more easily acquired data on changes in patch occupancy to make predictions about patch colonization and extinction rates.
\end{abstract}

RÉSUMÉ. Six espèces de pics de grande taille $(\geq 120 \mathrm{~g})$ ont un statut considéré comme étant de préoccupant à en voie de disparition par l'Union internationale pour la conservation de la nature (UICN). Le paradigme des petites populations assume que ces populations vont probablement disparaître à moins d'une augmentation de leur effectif, mais les influences combinées de population de départ et des taux démographiques, c.-à-d. le taux de survie annuel des adultes et la fécondité, peuvent permettre la persistance des populations de ces espèces. Nous avons utilisé un modèle stochastique par classes pour population unique aux données démographiques disponibles pour les pics des genres Dryocopus et Campephilus. En particulier, nous avons déterminé les changements prédits des taux d'extinction, c.-à-d., la proportion des populations simulées qui sont disparues en moins de 100 ans, aux changements proportionnels de six paramètres. À notre connaissance, ceci est la première étude qui évalue l'influence combinée de l'effectif de la population initiale et des taux démographiques afin de mesurer la persistance des pics de grande taille. Dans le pire des scénarios, le temps médian jusqu'à l'extinction était de 8 ans (min.-max.: 1-50). De toutes

${ }^{1}$ Warnell School of Forestry and Natural Resources University of Georgia
Athens, Georgia, USA 30602, ${ }^{2}$ Tved 107 C, DK-6270 Tønder, Denmark

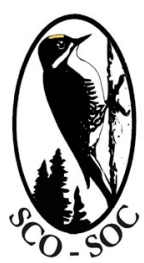

Sponsored by the Society of Canadian Ornithologists and Bird Studies Canada

Parrainée par la Société des onithologistes du Canada et Études d'oiseaux Canada

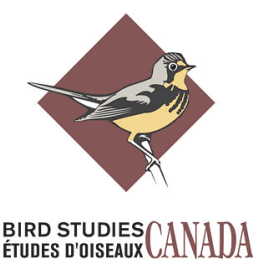


les combinaisons des autres valeurs intégrées dans le modèle, l'accroissement de la population initiale par une femelle provoquait, en moyenne, une diminution de $0.4 \%$ à 3.2\% (min.-max.: 0\%-28\%) du taux d'extinction. L'accroissement de l'effectif de la population initiale de 5 à 30 résultait en des taux d'extinction $<0.05$ sous certaines conditions: (1) toutes les valeurs intégrées étaient intermédiaires, ou (2) l'effet d'Allee était présent et le taux de survie des adultes $\geq 0.8$. Selon notre modèle, ces espèces peuvent persister en étant rares, avec aussi peu que cinq femelles, et sont donc difficile à détecter, à condition qu'elles maintiennent un recrutement $\geq 1.1$ femelle par femelle adulte chaque année et un taux de survie à l'état adulte $\geq 0.8$. Bien qu'une analyse de viabilité des populations (AVP) fondée sur la démographie soit utile pour prédire les changements des taux d'extinction selon différents scénarios pour les attributs du cycle vital, la prochaine étape pour la modélisation de ces populations devrait incorporer des données plus faciles à obtenir quant aux changements d'occupation des parcelles d'habitats afin de pouvoir prédire la colonisation de ces parcelles et les taux d'extinction.

Key Words: Allee effect; Campephilus principalis; Dryocopus; endangered species; multiple-variable perturbation analysis; stage-based model.

\section{INTRODUCTION}

One of the most difficult challenges facing conservation biology is providing guidelines for endangered species management in the face of limited biological knowledge about the causes and factors driving extinction risk. This problem is illustrated by six large-bodied, $\geq 120 \mathrm{~g}$, woodpecker species in the genera Campephilus and Dryocopus that are listed as near threatened to critically endangered (IUCN 2006). These two genera are the sole members of the Campephelini tribe, which is unique among the woodpeckers for large body sizes and breeding season diets consisting mostly of large, wood-boring beetle larvae (Winkler et al. 1995). Population declines of the imperiled Campephelini species have been attributed to loss of suitable breeding habitat, which likely includes tracts of mature, dying, and/or dead trees (Winkler et al. 1995). Life histories of these species are poorly understood, but this information is crucial to direct conservation and to ensure population persistence. Four of these imperiled species have highly restricted ranges within South America, including Helmeted Woodpecker (Dryocopus galeatus), Black-bodied Woodpecker (Dryocopus shulzi), Guayaquil Woodpecker (Campephilus gayaquilensis), and Imperial Woodpecker (Campephilus imperialis). The Andaman Woodpecker (Dryocopus hodgei) is restricted to the Andaman Islands south of India. The member of this tribe that has received the most recent attention is the Ivory-billed Woodpecker (Campephilus principalis), which was originally found throughout bottomland forests of the southeastern United States and Cuba (Jackson 2002). This species was thought to have become extinct, but recent evidence suggests that the species may persist in parts of its former range (Fitzpatrick et al. 2005, Hill et al. 2006). Improving our understanding about the factors influencing population viability of rare, large-bodied woodpeckers will help guide research and conservation for the Campephelini tribe.

Small population size imposes obvious constraints on population dynamics, and this limitation is often referred to generally as the small population paradigm (Caughley 1994). Past theoretical and empirical work predicts that population viability should increase with increasing initial population size both among and within species (Pimm et al. 1988, Letcher et al. 1998, Reed et al. 2003). Individuals in small or fragmented populations may have fewer opportunities to locate mates because of a skewed local sex ratio and/or physical isolation from conspecifics, henceforth the Allee effect (Allee 1938, Courchamp et al. 1999). Low demographic rates, i.e., low annual adult survival and fecundity (Beissinger 2000) or high annual variability in these demographic rates in response to environmental variation (Stacey and Taper 1992), also can lead to extinction of small populations. Persistence of small populations of species with high adult survival rates and low fecundity, such as large-bodied woodpeckers, may therefore be driven by a combination of population size, demographic rates, and the Allee effect. The combined importance of these factors, however, remains 
poorly understood (Sæther et al. 1996, Katzner et al. 2006). Resolving this issue has important implications for setting priorities in research and management of endangered species.

Population viability analysis (PVA) is a useful tool for providing reliable guidelines for research, management, and recovery of endangered species (Brook et al. 2000). There are many different types of PVAs, the simplest being a deterministic, singlepopulation model, and one of the most complex being a stochastic, spatially explicit, individualbased genetic model (Beissinger and Westphal 1998). The number of required input parameters increases with model complexity, and so the challenge is to construct a model that accommodates both the objectives of the study and the data available.

Life history and demographic data are extremely limited for large-bodied woodpeckers of conservation concern (Winkler et al. 1995, Jackson 2002, IUCN 2006). The only detailed study on any of these species was by Tanner (1942), who reported habitat associations, home range sizes, and fecundity for a population of Ivory-billed Woodpeckers in Louisiana, USA. To our knowledge, there are no published annual survival rates or dispersal patterns for adults or juveniles in the genus Campephilus, but such data have been reported for other woodpecker species. In particular, two recent reviews of published studies provide estimates of annual adult survival, henceforth, survival rates for woodpeckers of Europe and North America (Pasinelli 2006, Wiebe 2006). To our knowledge, only three such datasets exist for members of the Campephelini tribe. First, Bull and Jackson (1995) reported estimates of fecundity and survival for Pileated Woodpeckers (D. pileatus) based on a 9-yr study of nests and color-ringed individuals in northeastern Oregon, USA. Second, Bonar (2001) also reported demographic rates for Pileated Woodpeckers, but this work was based on a 5-yr study of nests and radio-tagged individuals in westcentral Alberta. Finally, a 24-yr data set of nesting and mark-resight data exists for Black Woodpeckers (D. martius) of southern Denmark and northern Germany (Mattsson and Christensen, unpublished data). We combined data sets on these species to identify the range of possible values for means and variances in survival and fecundity for imperiled Campephelini woodpeckers.
The objectives of our study are to: (1) address the main assumption of the small population paradigm, that populations with low numbers of individuals intrinsically have a high probability of extinction; (2) predict the number of years to extinction under two biologically reasonable scenarios for demographic rates and population size; (3) assess the relative influence of population size, demographic rates, and interactions among them for predicting extinction rate; and (4) evaluate the likelihood that small populations of Campephilus woodpecker species may have persisted through the latter portion of the 20th century until modern times. To accomplish these objectives, we developed a stochastic, discrete, stage-based, single-population PVA to examine the relative influence of initial population size, demographic rates, and their interactions on population persistence for largebodied woodpeckers. Thus, our aim was to investigate the combined influence of input parameters on relative risk of extinction rather than absolute risk of extinction. This approach is generally favored when there is a high amount of uncertainty regarding the demographic data used for the PVA (McCarthy et al. 2003). We used these results to make inferences about the relative influences of initial population size and demographic rates on population viability of largebodied woodpeckers. We then provide specific implications for the persistence of Ivory-billed Woodpeckers. Finally, we compare our findings with similar modeling efforts for other species and emphasize that inferences from our model should be used as a guide for future research on rather than immediate management of the Campephelini tribe. To our knowledge, this is the first study to evaluate the combined influence of initial population size and demographic rates for the persistence of largebodied woodpeckers.

\section{METHODS}

\section{Population model design}

We used a stage-based stochastic model that considers only females in the population and operates on an annual time step (Fig. 1). The two life stages include after-hatch-year females and hatch-year females, henceforth, adults and juveniles, respectively. The simulation begins in the first year by determining whether each adult produces a juvenile and whether the adult survives 
to breed the next year. After summing the number of juveniles and surviving adults to yield annual population size, the simulation repeats these steps in each of the following $99 \mathrm{yr}$ unless the number of females drops to zero, i.e., population goes extinct.

The model requires seven parameters as input, including the initial number of adults, two parameters that comprise a functional form representing an Allee effect, annual adult survival rate, and global means and variances for fecundity, i.e., number of juveniles per adult. To model the Allee effect, we calculated the annual mean probability of breeding $\left(B_{\text {it }}\right)$ for each individual throughout each simulation using the following function:

$$
\frac{l}{l+e^{\left(-\left(\beta_{0}+N_{t} \beta_{0}\right)\right)}}
$$

where $N_{t}$ is the population size in that year, $\beta_{0}$ is the intercept, and $\beta_{a}$ is the slope of the relationship, $i$. e., Allee effect. In particular, the intercept defines the minimum number of adults required for breeding to occur, and the slope represents the steepness of the relationship between population size and probability of breeding (Fig. 2).

For each year in the simulation, the model uses the input-global means and variances to randomly select means for annual adult survival rate $\left(S_{t}\right)$ and fecundity $\left(F_{t}\right)$ from the logitnormal and lognormal distributions, respectively. These distributions best fit 24-yr-specific survival rates and fecundity estimates for Black Woodpeckers (Mattsson and Christensen, unpublished data). Although the beta distribution is more commonly used to model binary responses, this distribution becomes skewed to the right when the mean and variance exceed 0.9 and 0.4 , respectively, and fit the data poorly. We used PROC GENMOD to evaluate goodness-of-fit (SAS Institute Inc. 2004).

For each individual in a particular year, the model draws random values for survival, fecundity, and if an Allee effect is present, probability of breeding, based on their respective annual means from probability distributions. In particular, the model draws a random binary outcome $(0,1)$ for adult survival from a Bernoulli distribution based on the year-specific rate drawn from the logitnormal distribution. When an Allee effect is present, the model draws a random binary outcome for an attempt to breed that year from the Bernoulli distribution, based on the probability of breeding calculated earlier. Otherwise, the probability of breeding is 1 . The model also draws a random integer for fecundity from the Poisson distribution with a year-specific mean drawn earlier from the lognormal distribution. The annual population size is therefore determined as follows:

$$
N_{t}=\sum_{i=1}^{N_{t-1}}\left[\operatorname{Bernoulli}\left(S_{t}\right)+\operatorname{Bernoulli}\left(B_{t}\right) \operatorname{Paisson}\left(F_{t}\right)\right]_{i}
$$

\section{Population model assumptions}

This model assumes that: (1) juveniles may reproduce in the year following their hatch year; (2) input values for expected rates of annual adult survival and fecundity and their respective variances remain constant throughout the population each year, although the realized annual rates vary stochastically; (3) annual adult survival and fecundity, henceforth, demographic rates, are independent of themselves and of population density, except for an Allee effect on fecundity; and (4) expected rates of annual adult survival and fecundity and their respective variances remain constant among years, except for an Allee effect on fecundity, although the realized annual rates vary stochastically.

Although more life history data are needed on large woodpeckers to accurately address each of these assumptions, we can justify them or provide some potential consequences for violating each. The first assumption may be violated, because the Magellanic Woodpecker delays breeding until the third year (Ojeda 2004), but both Black Woodpeckers (Christensen 2006) and Pileated Woodpeckers (Bull and Jackson 1995) normally breed in their second year. Rather than relaxing this assumption directly, we instead investigated how predicted extinction rate changed in response to variation in mean fecundity. According to our preliminary analyses, lowering mean individual fecundity in the model has the same effect as increasing the rate of delayed breeding across the 
Fig. 1. Flow diagram showing algorithm used for each iteration in stochastic, female-focused, stagebased, discrete population viability analysis for large-bodied woodpeckers. Probabilities are abbreviated as follows: $\mathrm{P}(\mathrm{jvs})=$ number of juveniles produced/adult, which is drawn from the Poisson distribution; $\mathrm{B}(\mathrm{ads})=$ survival outcome for each adult female, which is drawn from a Bernoulli distribution. Solid arrows indicate either "yes" or forward progression of the model. Dashed arrow indicates "no." Processes inside the dotted box are repeated for each adult female and each year in the model population.

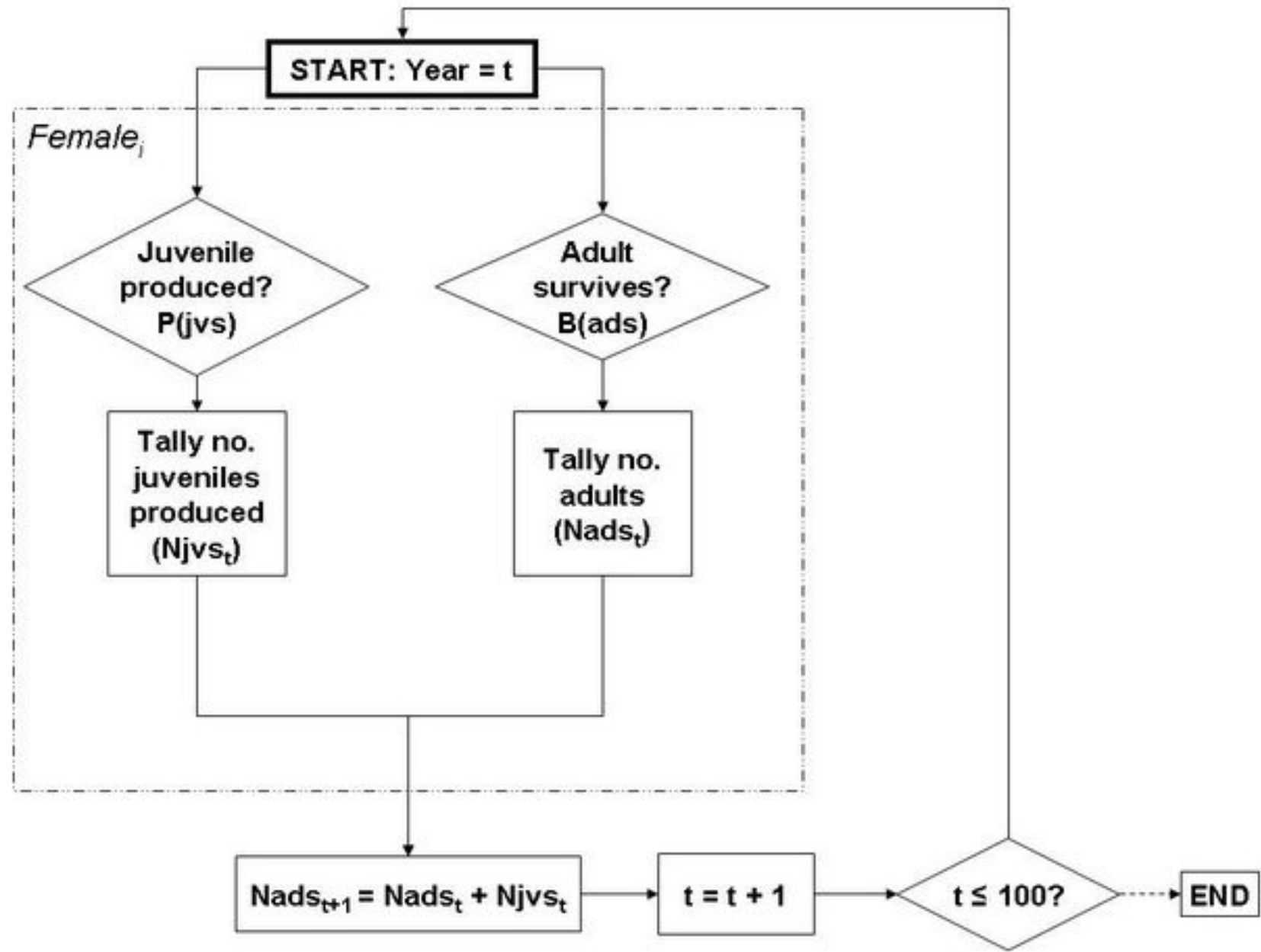

population. Furthermore, population dynamics of species with high survival rates have been shown to be relatively insensitive to the level of fecundity in the youngest age class (Sæther et al. 1996). The second assumption may be violated if territories vary in qualities that would affect these demographic rates. Forest patches that are young or isolated may have insufficient food resources to maintain recruitment rates compared with those that are older or less isolated (Letcher et al. 1998). Once more data on habitat quality and demographics become available, this assumption can be relaxed. If annual adult survival rate covaries with fecundity each year or if either of these demographic rates is density-dependent, then the third assumption is violated. Results from a 24-yr study of Black 
Fig. 2. Range of Allee effects used in a perturbation analysis of a stage-based, discrete, stochastic population viability analysis for large woodpeckers. The intercept $\left(\beta_{0}\right)$ and slope $\left(\beta_{a}\right)$ of the relationship between current population size and probability of breeding decreases as the Allee effect becomes stronger. The intercept and slope are shown to the right of each curve $\left(\beta_{0}, \beta_{a}\right)$. Population sizes exceeding 2,5, and 11 ensure that all individuals in the population will attempt to breed under the three scenarios, respectively.

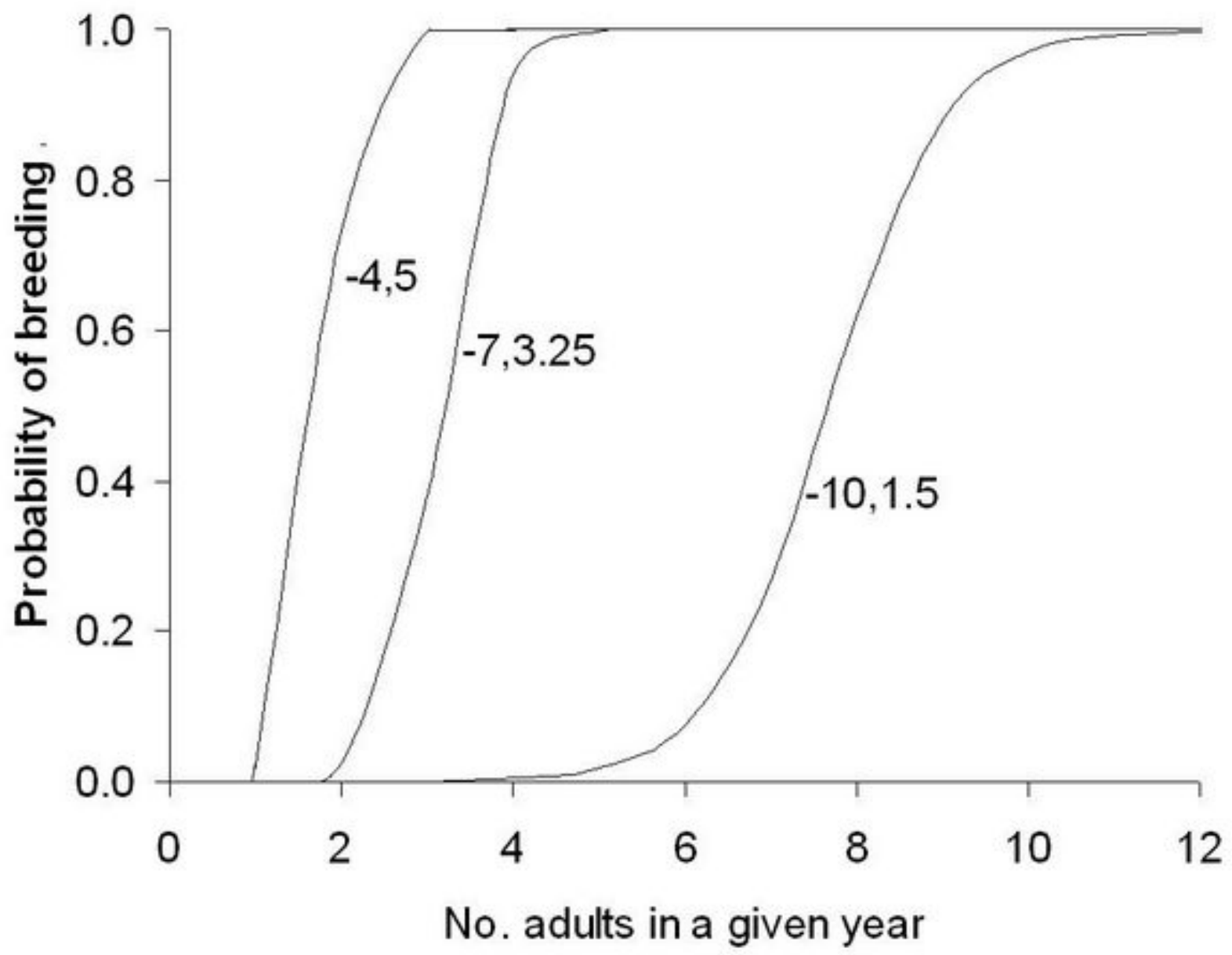

Woodpeckers, however, indicate that these demographic parameters vary independently of themselves and of population density (range: 0.080 0.220 pairs $/ \mathrm{km}^{2}$ within a forest tract; Mattsson and Christensen, unpublished data). Past modeling efforts have indicated that PVAs are fairly robust to violation of the density-independence assumption for species with slow or declining population growth rates (Sabo et al. 2004). If mast cycles, climate change, or periodic disturbances such as floods or tornadoes affect demographic rates (Beissinger 1995, Sillett et al. 2000, Schmidt and Ostfeld 2003), then the fourth assumption would be violated. 


\section{Population model parameterization}

We identified extreme values for each input parameter using both published and unpublished studies on large-bodied woodpeckers (Table 1). We work under the assumption that data for these species represents the possible range of population parameters for our target species.

We chose an upper range of initial population size after rounding up to 30 from the estimated number of remaining breeding Ivory-billed Woodpecker pairs in the early 20th century (i.e., 24; Tanner 1942). By using a minimum of five individuals in the simulation, we were able to apply assumptions about the ability of these individuals to breed, and in essence, examining a minimum effective population size of 1, i.e., Allee effect. The model also capped the population at 50 adults, which is based on the assumption that the amount of suitable habitat would support limited population growth beyond the maximum number of initial adults. Capping the population was necessary to avoid an unlimited, exponential increase in processing time of the simulation for a rapidly growing population, because the simulation draws values for fecundity and survival by individual adult each year.

The range of mean fecundity values also was based on values reported for Ivory-billed Woodpeckers (Tanner 1942). To obtain the range of variance in fecundity, we first multiplied the low and maximum values for mean fecundity by the mean coefficient of variation in fecundity reported for Pileated Woodpeckers (0.13; Bonar 2001) and Black Woodpeckers (0.072; Mattsson and Christensen, unpublished data), respectively. We then squared the result of this multiplication to obtain the upper and lower limits for the variance. In this way, we scaled the variance according to the means used in our analysis.

For the range of mean survival rates, we examined the relationship between clutch size and survival using published and unpublished estimates for woodpeckers. Whenever possible, we paired estimates of survival and clutch size from a single population; otherwise, we used mean estimates across populations. We constructed a linear model, with logit-transformed survival rate as the response variable and clutch size as the predictor variable. We used PROC GENMOD in SAS to obtain maximum-likelihood estimates for this model (SAS Institute Inc. 2004). As predicted from avian life history theory (Martin 1995), there was a negative relationship between clutch size and survival for North American and European woodpeckers (Fig. 3 ). To our knowledge, there are no survival estimates for tropical or Campephilus woodpeckers. Tanner (1942) reported a mean clutch size, i.e., number of male and female offspring/nest before hatching, of 2.9 for Ivory-billed Woodpeckers. Based on this estimate and the relationship between survival and clutch size (Fig. 3), we assumed a mean survival rate between 0.7 and 0.9. Many of these survival rates were based solely on resightings of marked individuals and did not account for individuals potentially leaving the study area. Therefore, these survival rates potentially underestimate true survival (Anders and Marshall 2005). We therefore examined the upper range of predicted survival rates for a clutch size of 2.9. Mean annual juvenile survival rate was held constant at one-half the annual adult survival rate throughout the simulations, which is $10 \%$ less than the ratio of juvenile to adult survival rates for Red-cockaded Woodpeckers (i.e., 3:5; Maguire et al. 1995). Furthermore, this assumption has been used traditionally in studies that lack sufficient information to estimate juvenile survival directly (Anders and Marshall 2005).

To obtain the range of variances in adult survival, we multiplied the low and maximum values for mean adult survival rate by the mean coefficient of variation in fecundity reported for Pileated Woodpeckers (0.067; Bonar 2001) and Black Woodpeckers (0.25; Mattsson and Christensen, unpublished data), respectively. As with the variances in fecundity, we then squared the result of this multiplication to obtain the upper and lower limits for the variance. To our knowledge, there are no data for modeling an Allee effect in a small or sparse population of large-bodied woodpeckers. We therefore used an ad hoc approach of entering trial values for $\beta_{0}$ and $\beta_{a}$ to represent biologically plausible functional forms (Fig. 2).

\section{Years of persistence}

To investigate a range of possible outcomes in the model, we first simulated years of persistence, i.e., the number of years until extinction $\left(N_{t}=0\right)$ in the simulated population. In particular, we considered two scenarios, both of which ignored the Allee effect. For a worse-case scenario, we used the following input values: (1) low initial population 
Fig. 3. Relationship between annual adult survival rates and mean clutch sizes of woodpecker species. The solid line indicates the mean, and the dashed lines indicate the $95 \%$ confidence limits of the regression line. The logit-transformed intercept and slope of the model were $1.97 \pm 1.10$ and -0.400 \pm 0.178 (estimate $\pm 95 \%$ CI), respectively. (a) Lesser Spotted Woodpecker (Dendrocopos minor), (b) Middle Spotted Woodpecker (Dendrocopos medius), (c) Great Spotted Woodpecker (Dendrocopos major), (d) White-backed Woodpecker (Dendrocopos leucotos), (e) Three-toed woodpecker (Picoides tridactylus), (f) Black Woodpecker (Mattsson and Christensen, unpublished data), (g) Black Woodpecker (Rolstad et al. 1995), (h) Pileated Woodpecker (Bonar 2001), (i) Northern Flicker (Colaptes auratus), (j) Red-naped Sapsucker (Sphyrapicus nuchalis), (k) Red-bellied Sapsucker (Melanerpes carolinus), (1) Acorn Woodpecker (Melanerpes formicivorus), (m) Golden-fronted Woodpecker (Melanerpes aurifrons), (n) Red-bellied Woodpecker (Melanerpes carolinus), (o) Redheaded Woodpecker (Melanerpes erythrocephalus), (p) Red-cockaded Woodpecker (DeLotelle and Epting 1992), (q) Red-cockaded Woodpecker (Walters et al. 1988, Labranche and Walters 1994), (r) Downy Woodpecker (Picoides pubescens), (s) Hairy Woodpecker (Picoides villosus), (t) Nuttall's Woodpecker (Picoides nuttallii). Circles indicate that the clutch size and survival rate were obtained from the same population. Otherwise, clutch sizes were obtained from Winkler et al. (1995), and survival rates were obtained from Pasinelli (2006) and Wiebe (2006) for European (a-g) and North American (h-t) species, respectively.

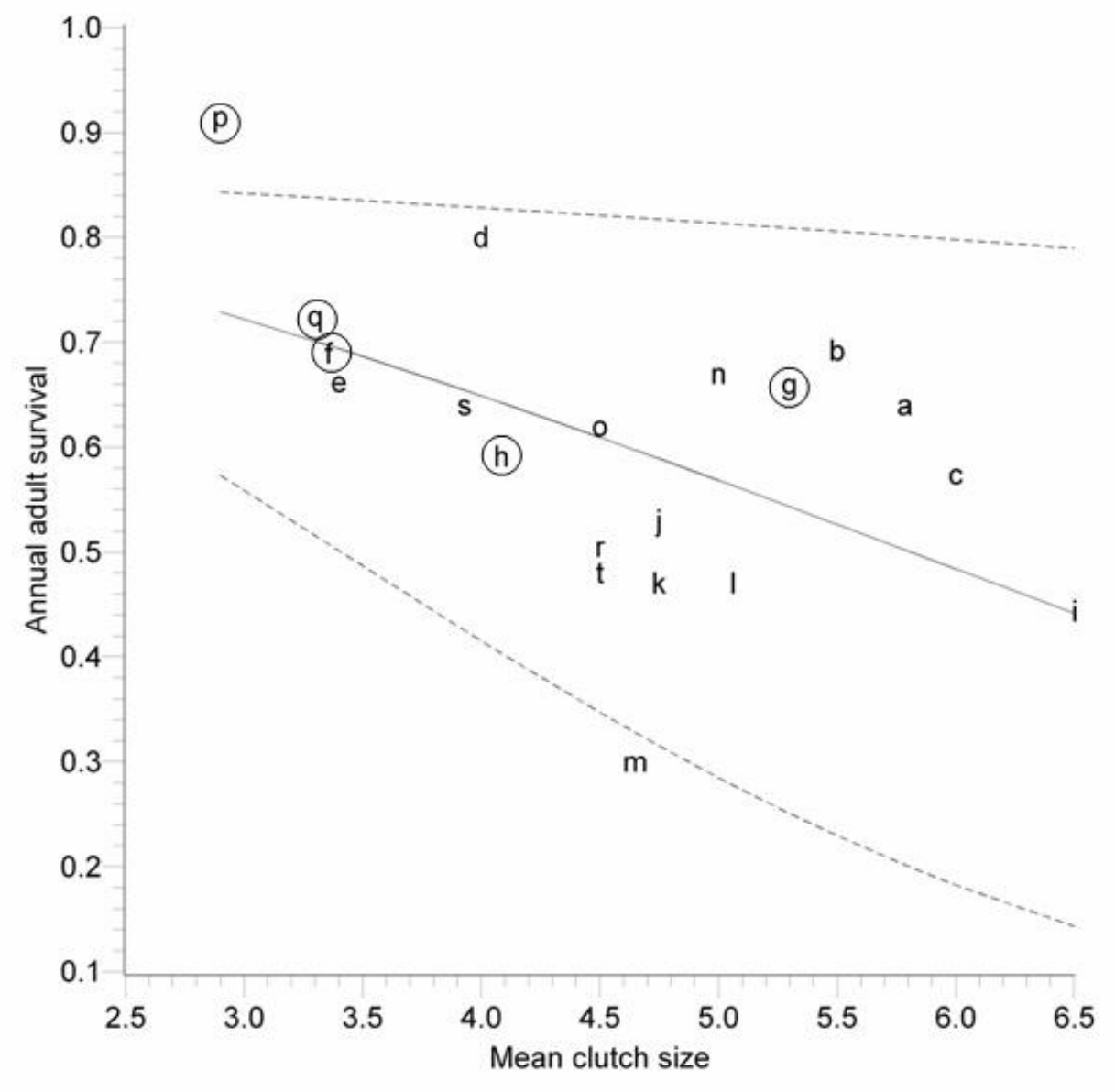


size, (2) low values for mean demographic rates, and (3) high values for variance in demographic rates (Table 1). For a better-case scenario, we used intermediate values for each of the input parameters (Table 1). We ran 200 independent, 100-yr simulations for each scenario using the programming language Python Version 2.4.2 (van Rossum 2006).

\section{Perturbation analysis}

Because of the discrete nature of our simulation, $i$. e., whole numbers of adults, we used a multiplevariable perturbation analysis to evaluate model behavior in response to coarse- and fine-scale changes in the input parameters. Such a perturbation analysis can provide insight as to which population parameters have the largest relative effect on extinction rate (Beissinger and Westphal 1998). In particular, some input values were held constant, whereas others were altered by large and small amounts while conducting coarse- and fine-scale perturbation analyses, respectively.

Preliminary analyses indicated that extinction rates, i.e., proportion of simulations in which population went extinct before year 100, were sensitive to variation in all five input parameters. To limit the number of possible combinations to consider at once, we ran three separate analyses to examine the relative influence of each parameter on extinction rate. In all analyses, we varied the initial number of adults to place special emphasis on comparing the relative influence of population size and demographics on predicted rates of extinction.

In the first analysis, we examined the influence of demographic rates on extinction probability by holding the variances in the demographic parameters constant while varying their means across the range of possible values (i.e., minimum, intermediate, and maximum). Second, we examined the influence of variation in environmental stochasticity by holding the means for the demographic parameters constant while varying their variances across the range of possible values. In these first two analyses, we assumed there was no Allee effect. In the third analysis, however, we examined the influence of variation in the Allee effect on extinction rates by holding the variances in the demographic parameters constant while varying survival across the range of possible values and making fecundity a function of population size in a given year. Despite the demonstrated importance of the Allee effect for population persistence (Berec et al. 2007), empirical measures of this effect in large-bodied woodpeckers, to our knowledge, are unavailable. Thus, we chose values for the intercept and slope for the Allee effect to generate curves that represented biologically reasonable scenarios for a population of woodpeckers (Table 1). The Allee effect becomes stronger as the slope decreases, such that population sizes exceeding 2, 5, and 11 ensure that all individuals in the population will attempt to breed under the three scenarios, respectively.

In each analysis, the simulation model used all possible combinations of the three focal input values across three increments $\left(3^{3}=27\right)$ while modeling demographic and environmental stochasticity across 200 independent iterations. We ran trial simulations with 100-20,000 iterations for a subset of input parameter combinations that led to low rates of extinction (ca., 0.05). Although increasing the number of iterations leads mathematically to more precise probability estimates, i.e., lower variance, the mean and standard deviation of probabilities across predicted extinction rates for each number of iterations remained similar for $\geq 200$ iterations. Thus, running 200 iterations for each of the 27 parameter combinations was likely an accurate representation of model behavior beyond 200 iterations per combination. The predicted rate of extinction was defined as the proportion of iterations in which the population went extinct during the 100-yr simulation. We determined which combinations of input parameter values were necessary to remain at or below an extinction rate threshold of 0.05 . For convenience, we define this measure as the "acceptable" extinction risk. To run these simulations, we again used Python Version 2.4.2 (van Rossum 2006). For available programs to perform the stage-based, discrete population model and perturbation analysis, please see Mattsson (2008) http://coopunit.forestry.uga.edu/jo urnalarch/WoodpeckerPVA.

In addition to examining changes in predicted extinction rate in the coarse-scale perturbation analysis, we calculated the change in extinction rate relative to a small change in each input parameter across its range of possible values for each combination of input values, i.e., fine-scale perturbation analysis (Appendix 1). This small, proportional change is equal or proportional to an additional initial adult, which was the limiting factor for scaling our perturbation analysis across all input 
Table 1. Minimum, maximum, and intermediate input values used in perturbation analysis for a stagebased population model that predicts extinction rates of large-bodied woodpeckers. Instantaneous rate of population growth $(\lambda)$ represents the expected population trajectory in the absence of stochasticity in the model.

\begin{tabular}{|c|c|c|c|c|c|c|c|c|c|}
\hline \multirow[b]{2}{*}{ Parameter } & \multicolumn{4}{|c|}{ Mean } & \multicolumn{4}{|c|}{ Variance } & \multirow[b]{2}{*}{ Data sources } \\
\hline & $\Delta \theta^{a}$ & Min. & $\begin{array}{l}\text { Inte- } \\
\text { rm. }\end{array}$ & Max. & $\Delta \theta^{a}$ & Min. & Interm. & Max. & \\
\hline Initial number of adults & 1 & 5 & 17 & 30 & - & - & - & - & Tanner 1942 \\
\hline Fecundity & 0.039 & 0.67 & 1.06 & 1.65 & 0.002 & 0.0022 & 0.0160 & 0.051 & $\begin{array}{l}\text { Tanner 1942, Bonar 2001, Mattsson } \\
\text { and Christensen, unpublished data }\end{array}$ \\
\hline Annual adult survival rate & 0.008 & 0.7 & 0.8 & 0.9 & 0.004 & 0.0076 & 0.0394 & 0.096 & $\begin{array}{l}\text { Bonar 2001, Loehle 2005, Mattsson } \\
\text { and Christensen, unpublished data }\end{array}$ \\
\hline Population growth rate $(\lambda)^{\mathrm{b}}$ & - & 0.93 & 1.22 & 1.64 & - & - & - & - & $=S+F * 0.5 * S$ \\
\hline
\end{tabular}

${ }^{a}$ Constant used in fine-scale perturbation analysis (See Appendix 1).

${ }^{b}$ Calculation of female population growth rate is based on fecundity ( $F$ : number of female fledglings/ adult female) and annual survival $(S)$. The calculation also assumes that juvenile survival is one-half of adult survival, and females can breed $1 \mathrm{yr}$ after they hatch.

parameters. This fine-scale perturbation analysis is derived but differs from traditional sensitivity analysis, which involves differentiation of an output parameter with respect to an infinitesimal change in an input parameter (Williams et al. 2002).

\section{RESULTS}

\section{Years of persistence}

Under a worse-case scenario when no Allee effect was present, predicted years of persistence based on our 100-yr, stage-based, discrete, stochastic population model ranged from 1 to 32 with a median of 7 (Fig. 4). In contrast, under a better-case scenario in which all input parameters were held at intermediate values (Table 1), years of persistence ranged from 5 to 100 with a median of 100 . Based on this finding, extinction rates exceeded 0, i.e., years to extinction < 100, primarily for those combinations of input values that were below intermediate levels. Conversely, moderate to high initial population size and demographic parameters predicted population persistence.

\section{Coarse-scale perturbation analysis}

Despite much variation in extinction rates across input parameter values and analyses, a consistent result from the coarse-scale perturbation analysis was that an adult survival rate $\geq 0.8$ and mean fecundity $\geq 1.16$ were required for a low extinction rate (i.e., $\leq 0.05$; Fig. 5, Appendices 2-4). The predicted initial number of adult females required for a low extinction rate, however, was conditional on the values of the other parameters. Analyses of demographic rates variation, environmental variability, and Allee effect predicted persistence when there was a minimum of five initial adults, while assuming better-case scenarios for the other parameters (Appendices 2-4). Of these analyses, only the Allee effect produced conditions across all combinations of focal input values, whereby reducing the initial number of adults led to a predicted extinction rate of $>0.05$. In particular, when survival was $\geq 0.8$ and the initial number of adults increased from 5 to 30, the mean predicted extinction rate dropped from $>0.17$ to $<0.04$ (Fig. 5B). Increasing initial population size also led to persistence across a range of environmental stochasticity; when demographic rates and variance 
Fig. 4. Years of persistence under two scenarios in a stochastic, stage-based, discrete population model of large-bodied woodpeckers. For the better-case scenario, all input parameters were at their intermediate values, and there was no Allee effect. For the worse-case scenario, initial population size and mean values for annual adult survival and fecundity were held at low values, variances of these demographic rates were held at high values, and there was no Allee effect. The center horizontal line in each box represents the median, edges of boxes represent the interquartile range, whiskers represent the 10th and 90th percentiles, and the symbol $x$ indicates values beyond these percentiles. The 10th-90th percentiles were equal to 100 in the better-case scenario.

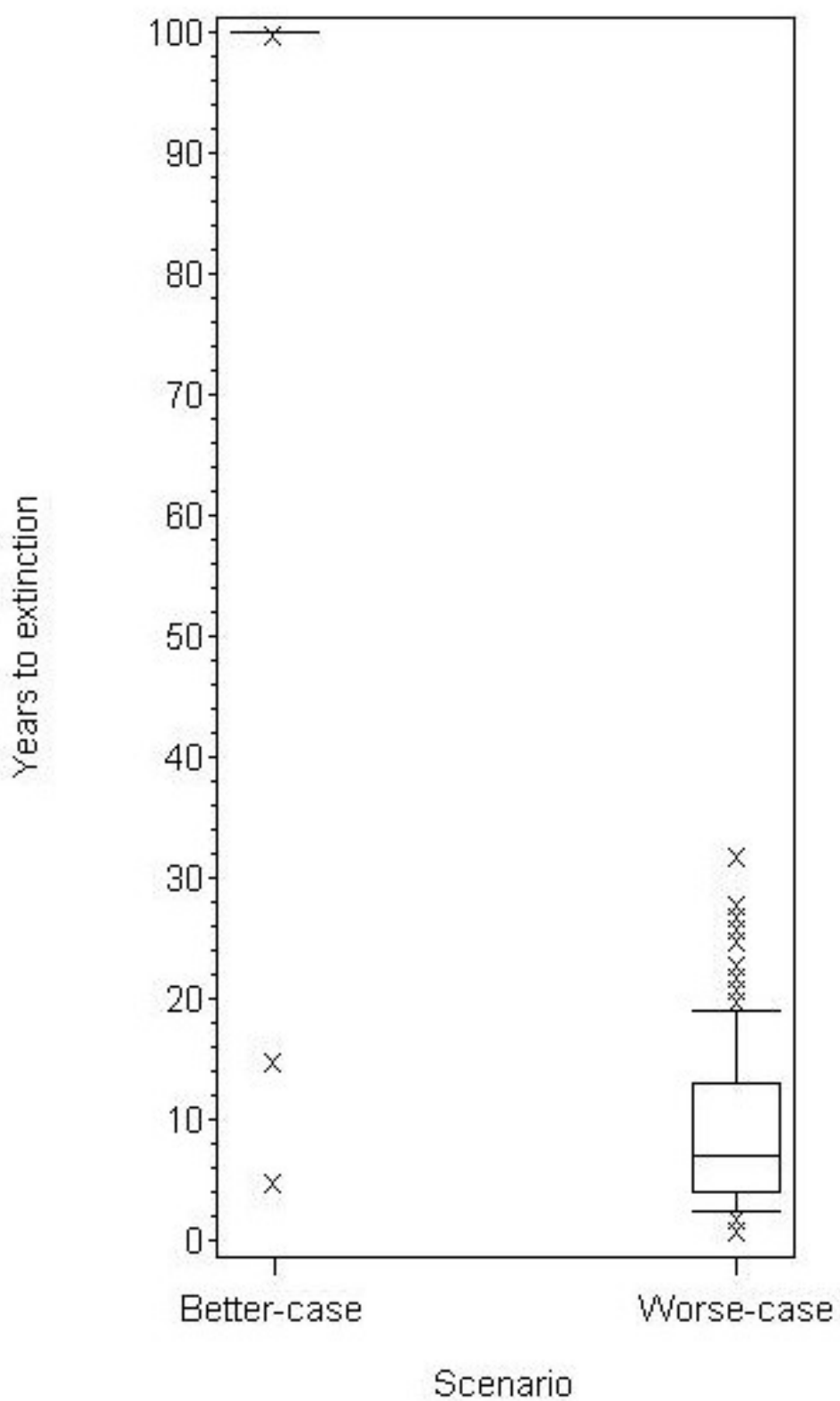


in survival were held at intermediate values, extinction rate dropped from 0.05 to $<0.02$ (Fig. 5A).

\section{Fine-scale perturbation analysis}

Our fine-scale perturbation analysis corroborated some of the patterns evident from the coarse-scale analysis, in which we compared extinction rates across the original combinations of input values for each analysis (Fig. 6). In particular, changes in extinction rate were variable among input parameters, combinations of input values, and analyses (Appendices 2-4). Changes were greatest, on average, in the analysis of the Allee effect (Fig. 6C). In this analysis, extinction rate was most responsive, on average, to variation in survival and initial number of adults. The lowest mean changes occurred in the analysis of environmental variation (Fig. 6B), in which mean survival and fecundity were held constant. When considering interactions among input parameters, changes reached maxima often under worse-case scenarios: (1) low survival and fecundity (Appendix 2); (2) high variance in survival and fecundity (Appendix 3); or (3) low number of initial adults, high survival, and strong Allee effect (Appendix 4). The greatest change was with respect to initial population size, and this occurred when survival and the Allee effect were high and initial population size was low (Appendix 4). In contrast, changes reached minima under better-case scenarios: (1) high survival or fecundity (Appendix 2); (2) high number of initial adults and low variance in survival (Appendix 3); or (3) high number of initial adults, intermediate or greater survival, and weak Allee effect (Appendix 4). Across analyses and combinations of the other input values, increasing initial population size by one female induced, on average, a $0.4 \%-3.2 \%$ (range: $0 \%-28 \%$ ) reduction in extinction rate.

\section{DISCUSSION}

Given a worse-case scenario for a small population of large-bodied woodpeckers that has a risky combination of demographic rates, i.e., low annual adult survival and fecundity (Beissinger 2000) and is highly responsive to environmental variability, our stochastic PVA predicted extinction within 40 yr. When considering all possible combinations of input parameters for this model, the predicted extinction rate depended on simultaneous variation among these parameters. Perturbation analysis is an important tool for examining the relative strengths of population parameters in driving measures of population viability (Beissinger and Westphal 1998, Williams et al. 2002), and our study is the first to apply this tool while investigating interactions among input parameters in a population viability analysis for large-bodied woodpeckers or other species with a similar combination of demographic rates. Extinction rates predicted by our model were driven by small changes in the individual parameters and combinations of the input parameters, including initial population size, mean survival, and fecundity, variance in annual adult survival and fecundity, and the Allee effect.

Our perturbation analysis indicated that the effect of initial population size on extinction rate depends on values of demographic parameters. In particular, increasing the initial population size from 5 to 30 conferred an acceptable risk of extinction (i.e., probability $\leq 0.05$ ) when an Allee effect was added and survival rate was at or above intermediate (i.e., $\geq 0.8$ ). When variance in survival and the means for survival rate and fecundity were held at intermediate values, increasing initial population size again conferred an acceptable risk of extinction. Thus, initial population size was important for population persistence under limited conditions. This finding is largely inconsistent with the small population paradigm as described, but not necessarily endorsed, by Caughley (1994). This paradigm states that population persistence is largely driven by the number of individuals in that population, as these few individuals are subject to stochastic events. Instead, our finding agrees with Lande (1993), who postulated that persistence of small populations depends not only on population size but also on the relative magnitudes of demographic rates and their associated variances. Therefore, we propose that populations with moderate levels for their demographic rates and respective variances can persist in low numbers despite environmental stochasticity, i.e., a demographic robustness paradigm. Instead of simply comparing the relative contribution of population parameters to persistence of threatened or endangered species, i.e., individual parameter perturbation sensitivity analysis (Letcher et al. 1998, Reed et al. 1998, Norris and McCulloch 
Fig. 5. Predicted rates of extinction while varying the initial number of adults in a stage-based, discrete, stochastic population viability analysis for large-bodied woodpeckers. Increasing the initial number of adults resulted in an extinction rate $\leq 0.05$, noted with gray line, when demographic rates were intermediate while their variances decreased (A), when an Allee effect was present while demographic rates and their variances were intermediate $(B)$, but not when demographic rates varied while their variances were intermediate (C). Whiskers represent 95\% confidence limits $(n=200)$.
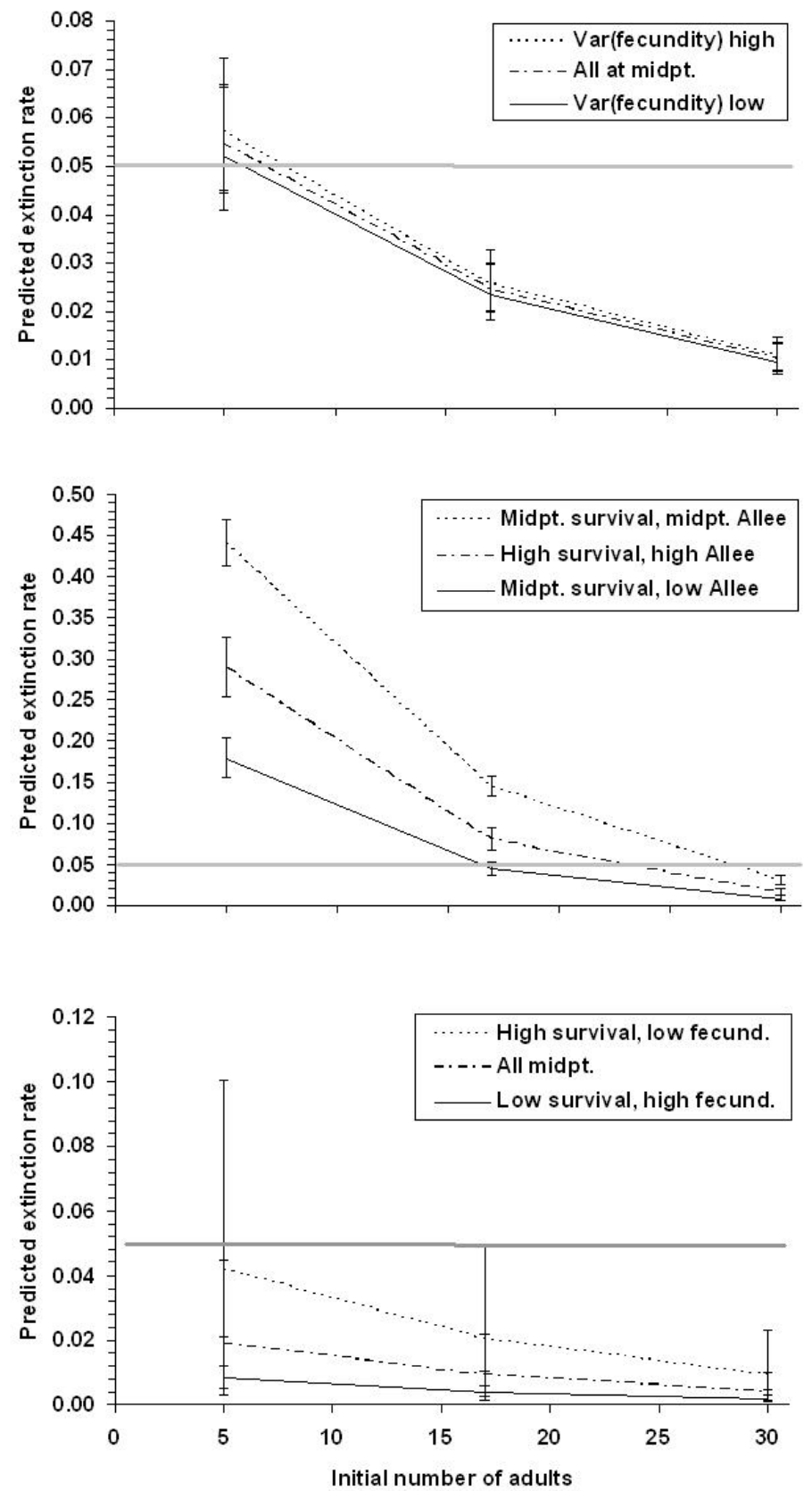
Fig. 6. Small, proportional changes in input parameters expected to decrease probability of extinction in a stage-based, discrete, stochastic population model for large-bodied woodpeckers. Each graph represents the set of mean changes from an analysis that focused on variation in particular drivers of population dynamics: (A) Variation in demographic rates: variances of annual adult survival and fecundity were held constant at intermediate values while either initial number of adults increased by 1 , annual adult survival increased by 0.008 , or fecundity increased by 0.039 ; (B) Environmental stochasticity: means for annual adult survival and fecundity were held constant at intermediate values while either lognormal variance in fecundity decreased by 0.0089 , initial number of adults increased by 1 , or the scaling parameter for the logitnormal variance in annual adult survival decreased by 0.0442 , and (C) Allee effect: variance in annual adult survival and mean and variance in fecundity were held constant at intermediate values while either the slope of the relationship between annual population size and probability of breeding increased by 0.14 , initial number of adults increased by 1 , or annual adult survival increased by 0.008 . Results displayed in each graph are based on 200 iterations across all possible combinations of input parameters. Whiskers represent $95 \%$ confidence intervals. The largest decreases in predicted extinction rate occurred when an Allee effect was present and an initial adult was added or annual adult survival rate was increased by a small, proportional amount.
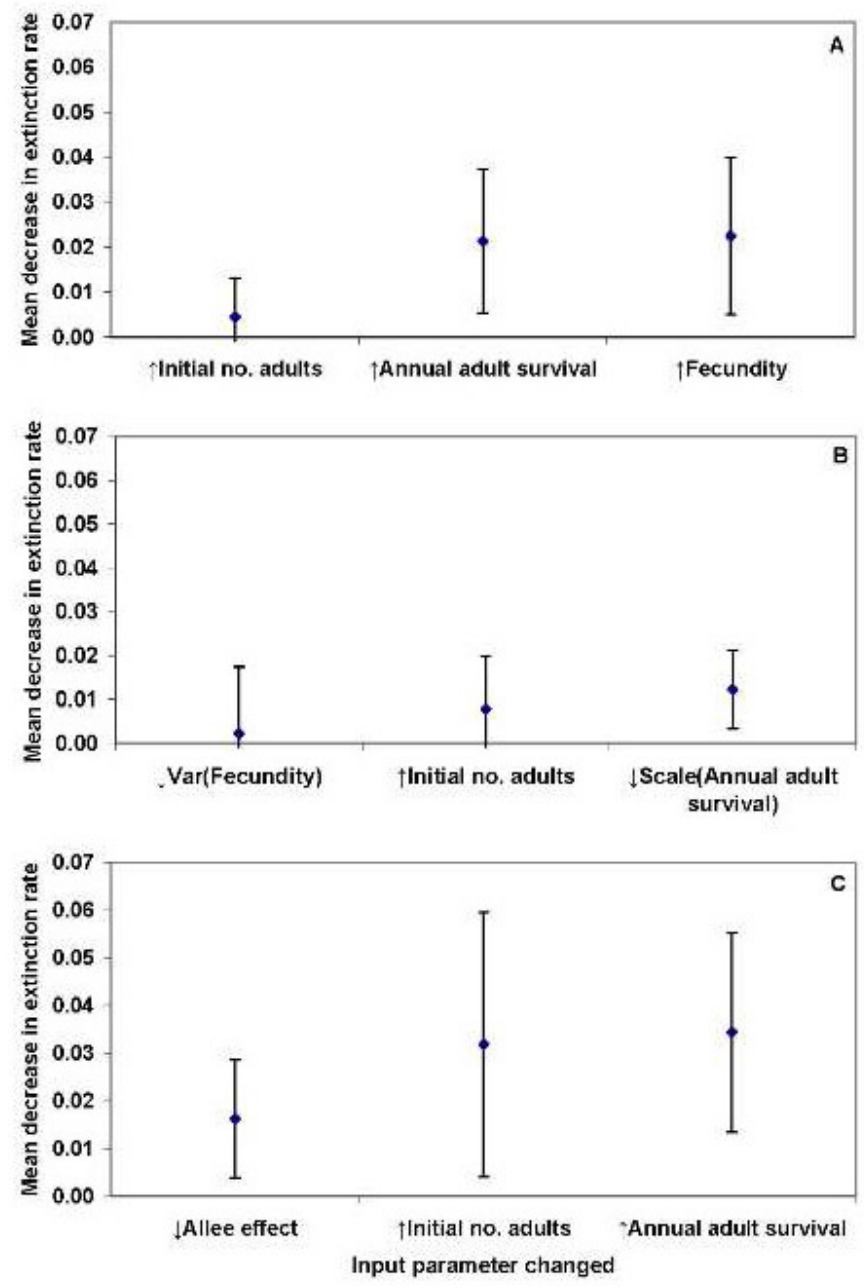
2003), researchers should consider the combined importance of initial population size and demographic rates for population persistence (Katzner et al. 2006).

\section{Comparisons with other studies}

Our findings are consistent with predictions from other studies that used stage-based models to examine the importance of initial population size and demographic rates. As the focal species from these studies exhibited ranges of parameters that were outside those used in our model, our similar findings may lead to a more general conclusion about the model-based parameters that drive extinction probability. Letcher et al. (1998) developed such a model for Red-cockaded Woodpeckers (Picoides borealis) and found that population stability was much more sensitive to variation in demographic rates than initial population size. Likewise, Stacey and Taper (1992) demonstrated that Acorn Woodpecker (Melanerpes formicivorus) population persistence time also was more sensitive to variation in demographic rates than initial population size. Another example of this model prediction is from a model of Snail Kite (Rostrhamus sociabilus) population viability. Kite survival rates and fecundity decline during periodic droughts, and consequently predicted population sizes at $100 \mathrm{yr}$ are inversely related to the simulated drought interval (Beissinger 1995). These ending population sizes were more sensitive to drought interval than to initial population size (Beissinger 1995). Finally, a sensitivity analysis of an agestructured, stochastic PVA for Imperial Eagles (Aquila heliaca) indicated that population growth rates were insensitive to initial population size but highly sensitive to survival rates followed by reproduction (Katzner et al. 2006). The eagle study is also one of very few that investigated synergistic effects among input parameters, but in doing so they reported only the relative strengths of each input parameter relative to all other parameters in the model. Therefore, our study differs in that we explicitly considered three-way interactions among input parameters. Nonetheless, results from these studies combined with our own tend to refute assumptions of the small population paradigm for these species.

In addition to environmental stochasticity, population persistence for cooperative-breeding woodpeckers has been shown to be most sensitive to parameters relating to immigration rates
(Middleton and Nisbet 1997). These include the spatial arrangement of territory clusters in the case of Red-cockaded Woodpeckers (Letcher et al. 1998). Population persistence of Spotted Owls (Strix occidentalis) has also been shown to be more sensitive to measures of spatial arrangement among individuals when compared to other parameters such as initial population size (Lamberson et al. 1992). In our simulations, we found that, when combined with an annual adult survival rate $\geq 0.8$, rates of extinction were highly sensitive to variation in the strength of an Allee effect. The most likely mechanisms for such an effect in populations of large-bodied woodpeckers include the inability to locate mates, which in turn relates to spatial arrangement of suitable habitat and sex ratio (Wells et al. 1998, Courchamp et al. 1999). Because these factors have not been measured, our hypothetical Allee effect remains the only approximation of the system.

Results from our study, combined with others that used stochastic models to explore population viability, allow us to make three general conclusions. First, when considered alone, initial population size has a weaker influence on extinction rates than do demographic rates. Second, it is important to consider interactions among population parameters rather than just focusing on one at a time. Third, initial population size becomes important for maintaining a low extinction rate only when an Allee effect is present or when demographic rates and variance in survival are intermediate.

\section{Implications for conservation of critically endangered Camphephilus woodpeckers}

Whereas our population model may be applied to any of the Campephelini Woodpeckers, conservation of the Ivory-billed Woodpecker has become a recent priority for the U.S. Fish and Wildlife Service. Although information about habitat requirements is limited, the species was historically associated with older bottomland forests of the southeastern United States, and they likely depended on these forests for food and nest sites (Jackson 2002). Extensive logging of bottomland forests in the southeastern United States, forest clearing in Cuba, and widespread hunting by collectors during the early 20th century are the likely causes for the nearextinction of the Ivory-billed Woodpecker (Jackson 2002, Snyder 2008). 
An interesting question that may be addressed is under what conditions could the species have persisted until today? First, based on our model, an initial population size of 5 females would have ensured likely persistence through modern times if annual demographic rates remained at least moderate, i.e., $\geq 1$. 1 recruited females/adult female and an adult survival rate $\geq 0.8$, and their variances remained at most moderate, i.e., $\leq 0.04$ for recruited females per adult female and $\leq 0.016$ for adult survival rate, (Appendices 2-4). Second, if there were 30 or more females, then the population would likely have persisted despite a relatively strong Allee effect, as long as variance in survival was at most moderate and either survival or fecundity was high (i.e., 1.65 recruited females per adult female or an adult survival rate of 0.9; Appendices 2-4). According to Tanner (1942), there were approximately 24 breeding pairs remaining across their range in the 1930s, but their demographic rates have remained virtually unknown. Such a retrospective interpretation of our model could apply to any species in the Campephilini tribe. The last confirmed breeding population of Imperial Woodpeckers, for example, was in the mid-20th century (Lammertink 1996). Thus, provided that these endangered woodpeckers maintain relatively high demographic rates, they can likely persist as small, and difficult-to-detect, populations. Although inbreeding depression may present problems for reproduction and recruitment in remnant woodpecker populations, heterozygosity of such populations can rebound following periodic matings between genetically disparate individuals (Caughley 1994). These species may, for example, overcome such population limitations by dispersing widely across suitable habitats.

Following the recent evidence of at least one Ivorybilled Woodpecker in the Big Woods region of eastern Arkansas (Fitzpatrick et al. 2005) and along the Choctawhatchee River in the panhandle of Florida (Hill et al. 2006), efforts are now underway to recover the Ivory-billed Woodpecker to the point at which its status is downgraded to "threatened" (USFWS 2005). One of the primary objectives of the recovery plan is to determine the number and geographic distribution of subpopulations needed to ensure a self-sustaining metapopulation (USFWS 2006). Of immediate importance to the recovery team, however, is the minimum population size needed to ensure population persistence for $100 \mathrm{yr}$ (C. Hunter, personal communication). The recovery plan will include this information while defining more specific guidelines for management and criteria for delisting the species. Based on our modeling results, however, we found that increasing initial population size only becomes important for lowering the extinction rate below 0.05 when an Allee effect is present and the annual adult survival rate is relatively high. Our results suggest that information on demographic rates are as important, if not more important, than current population size when identifying information needs and objectives for managing large woodpeckers, such as the Ivorybilled Woodpecker.

\section{Recommendations for future modeling efforts}

Although a PVA based on demographic rates is important for immediately modeling some of the factors influencing persistence of large-bodied woodpeckers, better estimates of population parameters and their interrelationships with each other and environmental conditions, e.g., habitat structure and composition, disturbance regimes, would lead to clearer predictions about the effects of management on population persistence. Population parameters that need more data include annual survival of juveniles and adults, variance in survival, fecundity, sex ratio, mate-search efficiency, and colonization, i.e., immigration. A perturbation analysis that examines the relative influence of all parameters would then be feasible and could resolve more clearly the important drivers of population dynamics. Obtaining reasonable estimates of these population parameters requires intensively studying a population over several generations (Beissinger and Westphal 1998). As large-bodied woodpeckers may have a generation time of $>2 \mathrm{yr}$, such a study would likely exceed a decade. Under a worse-case scenario, our model predicted that the median time to extinction for such species is $8 \mathrm{yr}$.

Given the urgency of protecting imperiled, largebodied woodpeckers, efficient methods for improving models of extinction risk are needed. We suggest that the next step for modeling these populations should incorporate recent advances in estimating rates of local colonization and extinction from occupancy with respect to environmental conditions. These estimates can be used to develop a patch-based population viability model (MacKenzie et al. 2003). These methods require replicated visits to a site within a season to account for imperfect detection (Mackenzie and Royle 
2005). Organized population and habitat monitoring efforts are now underway throughout the former geographic range of the Ivory-billed Woodpecker. Evidence of the woodpecker based on auditory and visual recordings (e.g., Hill et al. 2006) may be incorporated into such a modeling effort. Rather than relying solely on long-term studies of stagespecific survival and fecundity, a relatively short occupancy data collection effort can produce estimates needed for a patch-based population viability analysis. Such an analysis would supplement, rather than replace, a more standard demographic-based PVA as in our study. This integrative approach is especially amenable to rare and elusive species such as the Ivory-billed Woodpecker. The urgent need to understand and protect this and other species of conservation concern calls for new ways to leverage all available information to inform conservation. Future research should therefore include ways to combine patchoccupancy studies with more intensive studies of demographics into population viability analyses.

Responses to this article can be read online at:

http://www.ace-eco.org/vol3/iss2/art5/responses/

\section{Acknowledgments:}

We thank the U.S. Fish and Wildlife Service (USFWS) for funding via Piedmont CESU (Agency no. 401816J096) and the U.S. Geological Survey (USGS) for additional funding via Cooperative Agreement (Agency no. O2HQRU1551N088). The Georgia Cooperative Fish and Wildlife Research Unit is jointly sponsored by USGS, the University of Georgia, Georgia Department of Natural Resources, USFWS, and the Wildlife Management Institute. We thank J. Rolstad for sharing insights on a Black Woodpecker population in borealforests of Norway. We also thank C. T. Moore, J. P. Runge, and $K$. W. Stodola for contributing suggestions on this PVA. Finally, we thank S. R. Beissinger, B. R. Noon, T. D. Nudds, and an anonymous reviewer for providing comments on earlier versions of this manuscript.

\section{LITERATURE CITED}

Allee, W. C. 1938. The social life of animals. Norton, New York, New York, USA.

Anders, A. D., and M. R. Marshall. 2005. Increasing the accuracy of productivity and survival estimates in assessing landbird population status. Conservation Biology 19:66-74.

Beissinger, S. R. 1995. Modeling extinction in periodic environments: Everglades water levels and snail kite population viability. Ecological Applications 5:618-631.

Beissinger, S. R. 2000. Ecological mechanisms of extinction. Proceedings of The National Academy of Sciences of The United States of America 97:11688-11689.

Beissinger, S. R., and M. I. Westphal. 1998. On the use of demographic models of population viability in endangered species management. Journal of Wildlife Management 62:821-841.

Berec, L., E. Angulo, and F. Courchamp. 2007. Multiple Allee effects and population management. Trends in Ecology and Evolution 22:185-191.

Bonar, R. L. 2001. Pileated Woodpecker habitat ecology in the Alberta foothills. Dissertation. University of Alberta, Edmonton, Alberta, Canada.

Brook, B. W., J. J. O'Grady, A. P. Chapman, M. A. Burgman, H. R. Akcakaya, and R. Frankham. 2000. Predictive accuracy of population viability analysis in conservation biology. Nature 404:385-387.

Bull, E. L., and J. E. Jackson. 1995. Pileated Woodpecker (Dryocopus pileatus). Pages 1-20 in A. Poole and F. Gill, editors. The Birds of North America Number 148. The Academy of Natural Sciences, Philadelphia, Pennsylvania, and the American Ornithologists' Union, Washington, D. C., USA.

Caughley, G. 1994. Directions in conservation biology. Journal of Animal Ecology 63:215-244.

Christensen, H. 2006. Warum bauen Schwarzspechte (Dryocopus martius) neue Bruthöhlen? Ergebnisse aus dem deutsch-dänischen Grenzbereich. Corax 20:120-128. 
Courchamp, F., T. Clutton-Brock, and B. Grenfell. 1999. Inverse density dependence and the Allee effect. Trends in Ecology and Evolution 14:405-410.

DeLotelle, R. S., and R. J. Epting. 1992. Reproduction of the Red-cockaded Woodpecker in central Florida. Wilson Bulletin 104:285-294.

Fitzpatrick, J. W., M. Lammertink, M. D. Luneau, T. W. Gallagher, B. R. Harrison, G. M. Sparling, K. V. Rosenberg, R. W. Rohrbaugh, E. C. H. Swarthout, P. H. Wrege, S. B. Swarthout, M. S. Dantzker, R. A. Charif, T. R. Barksdale, J. V. Remsen, S. D. Simon, and D. Zollner. 2005. Ivory-billed Woodpecker (Campephilus principalis) persists in continental North America. Science 308:1460-1462.

Hill, G. E., D. J. Mennill, B. W. Rolek, T. L. Hicks, and K. A.Swiston. 2006. Evidence suggesting that Ivory-billed Woodpeckers (Campephilus principalis) exist in Florida. Avian Conservation and Ecology 1 (3):2. [online] URL: http://www.ace-eco.org/voll/iss3/ art2/.

International Union for Conservation of Nature (IUCN). 2006. IUCNRed List of threatened species. Available online at: www.iucnredlist.org.

Jackson, J. A. 2002. Ivory-billed Woodpecker (Campephilus principalis). Pages 1-28 in A. Poole, editor. The Birds of North America Number 711. The Academy of Natural Sciences, Philadelphia, Pennsylvania, and the American Ornithologists' Union, Washington, D.C., USA.

Katzner, T. E., E. A. Bragin, and E. J. MilnerGulland. 2006. Modelling populations of longlived birds of prey for conservation: a study of Imperial Eagles (Aquila heliaca) in Kazakhstan. Biological Conservation 132:322-335.

Labranche, M. S., and J. R. Walters. 1994. Patterns of mortality in nests of Red-cockaded Woodpeckers in the sandhills of south-central North Carolina. Wilson Bulletin 106:258-271.

Lamberson, R. H., R. McKelvey, B. R. Noon, and C. Voss. 1992. A dynamic analysis of Northern Spotted Owl viability in a fragmented forest landscape. Conservation Biology 6:505-512.

Lammertink, J. M. 1996. Status and conservation of old-growth forests and endemic birds in the pineoak zone of the Sierra Madre Occidental, Mexico. Institute for Systematics and Population Biology, University of Amsterdam, Amsterdam, The Netherlands.

Lande, R. 1993. Risks of population extinction from demographic and environmental stochasticity and random catastrophes. American Naturalist 142:911-927.

Letcher, B. H., J. A. Priddy, J. R. Walters, and L. B. Crowder. 1998. An individual-based, spatially explicit simulation model of the population dynamics of the endangered Red-cockaded Woodpecker, Picoides borealis. Biological Conservation 86:1-14.

Loehle, C., L. Irwin, D. Rock, and S. Rock. 2005. Are survival rates for Northern Spotted Owls biased? Canadian Journal of Zoology 83:1386-1390.

MacKenzie, D. I., J. D. Nichols, J. E. Hines, M. G. Knutson, and A. B. Franklin. 2003. Estimating site occupancy, colonization, and local extinction when a species is detected imperfectly. Ecology 84:2200-2207.

Mackenzie, D. I., and J. A. Royle. 2005. Designing occupancy studies: general advice and allocating survey effort. Journal of Applied Ecology 42:1105-1114.

Maguire, L.A., G. F. Wilhere, and Q. Dong. 1995. Population viability analysis for Red-cockaded Woodpeckers in the Georgia Piedmont. Journal of Wildlife Management 59:533-542.

Martin, T. E. 1995. Avian life-history evolution in relation to nest sites, nest predation, and food. Ecological Monographs 65:101-127.

Mattsson, B. J. 2008. Stage-based population model for large-bodied, imperiled woodpeckers. Georgia Cooperative Fish and Wildlife Research Unit, Warnell School of Forestry and Natural Resources, University of Georgia, Athens, Georgia, USA. Available online at: $h$ ttp://coopunit.forestry.uga. edu/journalarch/WoodpeckerPVA.

McCarthy, M. A., S. J. Andelman, and H. P. Possingham. 2003. Reliability of relative predictions in population viability analysis. Conservation Biology 17:982-989. 
Middleton, D. A. J., and R. M. Nisbet. 1997. Population persistence time: estimates, models, and mechanisms. Ecological Applications 7:107-117.

Norris, K., and N. McCulloch. 2003. Demographic models and the management of endangered species: a case study of the critically endangered Seychelles Magpie Robin. Journal of Applied Ecology 40:890-899.

Ojeda, V. S. 2004. Breeding biology and social behaviour of Magellanic Woodpeckers (Campephilus magellanicus) in Argentine Patagonia. European Journal of Wildlife Research 50:18-24.

Pasinelli, G. 2006. Population biology of European Woodpecker species: a review. Annales Zoologici Fennici 43:96-111.

Pimm, S. L., H. L. Jones, and J. Diamond. 1988. On the risk of extinction. American Naturalist 132:757-785.

Reed, J. M., C. S. Elphick, and L. W. Oring. 1998. Life-history and viability analysis of the endangered Hawaiian Stilt. Biological Conservation 84:35-45.

Reed, D. H., J. J. O'Grady, B. W. Brook, J. D. Ballou, and R. Frankham. 2003. Estimates of minimum viable population sizes for vertebrates and factors influencing those estimates. Biological Conservation 113:23-34.

Sabo, J. L., E. E. Holmes, and P. Kareiva. 2004. Efficacy of simple viability models in ecological risk assessment: does density dependence matter? Ecology 85:328-341.

Sæther, B. E., T. H. Ringsby, and E. Roskaft. 1996. Life history variation, population processes and priorities in species conservation: towards a reunion of research paradigms. Oikos 77:217-226.

SAS Institute Inc. 2004. SAS/STAT® 9.1 User's Guide. Version 8.02 edition, Cary, North Carolina, USA.

Schmidt, K. A., and R. S. Ostfeld. 2003. Songbird populations in fluctuating environments: predator responses to pulsed resources. Ecology 84:406-415.

Sillett, T.S., R. T. Holmes, and T. W. Sherry. 2000. Impacts of a global climate cycle on population dynamics of a migratory songbird. Science 288:2040-2042.

Snyder, N. F. R. 2008. An alternative hypothesis for the cause of the Ivory-billed Woodpecker's decline. Monographs of the Western Foundation of Vertebrate Zoology 2, Camarillo, California, USA.

Stacey, P. B., and M. Taper. 1992. Environmental variation and the persistence of small populations. Ecological Applications 2:18-29.

Tanner, J. T. 1942. The Ivory-billed Woodpecker. Research Report Number 1. Dover, New York, New York, USA.

United States Fish and Wildlife Service (USFWS). 2005. Recovery outline for the Ivorybilled Woodpecker (Campephilus principalis). USFWS, Atlanta, Georgia, USA. Available online at: http://www.fws.gov/ivorybill/IBWFinalRecover yPlanOutline.pdf.

United States Fish and Wildlife Service (USFWS). 2006. Draft recovery plan for the Ivorybilled Woodpecker (Campephilus principalis). USFWS, Atlanta, Georgia, USA.

van Rossum, G. 2006. Python language Website. Available online at: http://www.python.org.

Walters, J. R., P. D. Doerr, and J. H. Carter. 1988. The cooperative breeding system of the Redcockaded Woodpecker. Ethology 78:275-305.

Wells, H., E. G. Strauss, M. A. Rutter, and P. H. Wells. 1998. Mate location, population growth and species extinction. Biological Conservation 86:317-324.

Wiebe, K. L. 2006. A review of adult survival rates in woodpeckers. Annales Zoologici Fennici 43:112-117.

Williams, B. K., J. D. Nichols, and M. J. Conroy. 2002. Analysis and management of animal populations. Academic Press, San Diego, California, USA.

Winkler, H., D. A. Christie, and D. Nurney. 1995. Woodpeckers: a guide to the woodpeckers, piculets, and wrynecks of the world. Pica Press, East Sussex, UK. 
Appendix 1. Fine-scale perturbation analysis procedure.

\section{Please click here to download file 'appendix1.pdf'.}


Appendix 2. Fine-scale perturbation analysis of input demographic rates in a stochastic population viability analysis for large-bodied woodpeckers. See Appendix 1 for details on calculations.

Please click here to download file 'appendix2.pdf'. 
Appendix 3. Fine-scale perturbation analysis of input variables representing environmental variation in a stochastic population viability analysis for large-bodied woodpeckers. See Appendix 1 for details on calculations.

Please click here to download file 'appendix3.pdf'. 
Appendix 4. Fine-scale perturbation analysis of input demographic rates and an Allee effect in a stochastic population viability analysis for large-bodied woodpeckers. See Appendix 1 for details on calculations.

Please click here to download file 'appendix4.pdf'. 